\title{
Cave propagation factor for caving rate and drawpoint productivity forecasting at PTFI
}

ME Pierce Pierce Engineering, United States

R Campbell PT Freeport Indonesia, Indonesia

K Llewelyn PT Freeport Indonesia, Indonesia

M Fuenzalida Itasca Consulting Group, United States

K Simanjuntak PT Freeport Indonesia, Indonesia

A Kurniawan PT Freeport Indonesia, Indonesia

D Haflil PT Freeport Indonesia, Indonesia

F Meiriyanto PT Freeport Indonesia, Indonesia

S Rogers Golder Associates, Canada

\begin{abstract}
Monitoring of fracture limits, cave backs and drawpoint fragmentation at both the Grasberg Block Cave (GBC) and Deep Mill Level Zone (DMLZ) caves at PT Freeport Indonesia's operations suggest that Cave Propagation Factor (CPF), weak and persistent vein intensity and hydrofracture spacing exert a strong control on the caving rate and primary fragmentation within the cave back. CPF in this case is defined as the ratio of cave back stress to defected rock strength and can vary significantly across the cave back, both due to variability in vein mineralogy and intensity and complex cave back geometries. Cave back stress is understood through 3D elastic modelling of anticipated cave shapes (fracture limits) while point load indices, weak and persistent vein intensity and Synthetic Rock Mass (SRM) testing are used to understand the variability in strength and fragmentation potential of the sparsely jointed, massive to heavily veined rock mass domains. When coupled with predictive relations for secondary fragmentation, these ultimately led to the development of a methodology for forecasting of caving rate and primary fragmentation in the cave back, the fragmentation (including oversize and fines) reporting to the drawpoints and the associated hangup frequency and productivity. These forecasts are presented in the form of block models, forecast maps and drawpoint-based charts. When calibrated against monitored cave back and drawpoint performance these can be used to assist in more local cave back shaping and preconditioning (function of caving rate), recovery estimation and secondary breakage planning (function of productivity) and management of wet muck and mill throughput (function of fines entry).
\end{abstract}

\section{Introduction}

This paper describes a recently developed approach to cave productivity forecasting at PT Freeport Indonesia's (PTFI) Grasberg Block Cave (GBC) and Deep Mill Level Zone (DMLZ) mines that focusses on anticipating local caving rates, fines reporting to the extraction level and hangup frequency. The methodology was developed to assist production planning and a focus of the work was to develop a userfriendly, visual approach to forecasting the fragmentation-driven evolution in production performance that typifies caving in hard rock. As shown in Figure 1, productivity generally ramps up quickly with blasted ore reporting from the undercut (Category 1), followed by a drop as primary fragmentation reports from the 
bottom of the naturally caved ore column just above the undercut (Category 2). Secondary fragmentation gradually starts to become apparent (Category 3), eventually resulting in a significant reduction in large, hangup forming rocks and corresponding increase in fines (Category 4). In order to anticipate the form of this productivity curve in different sectors of the cave, the forecasting methodology developed at PTFI addresses cave back performance above each individual drawpoint, with a focus on primary fragmentation and caving rate (including the role of hydrofractures from preconditioning), followed by consideration of secondary fragmentation to anticipate conditions over the life of the drawpoint.

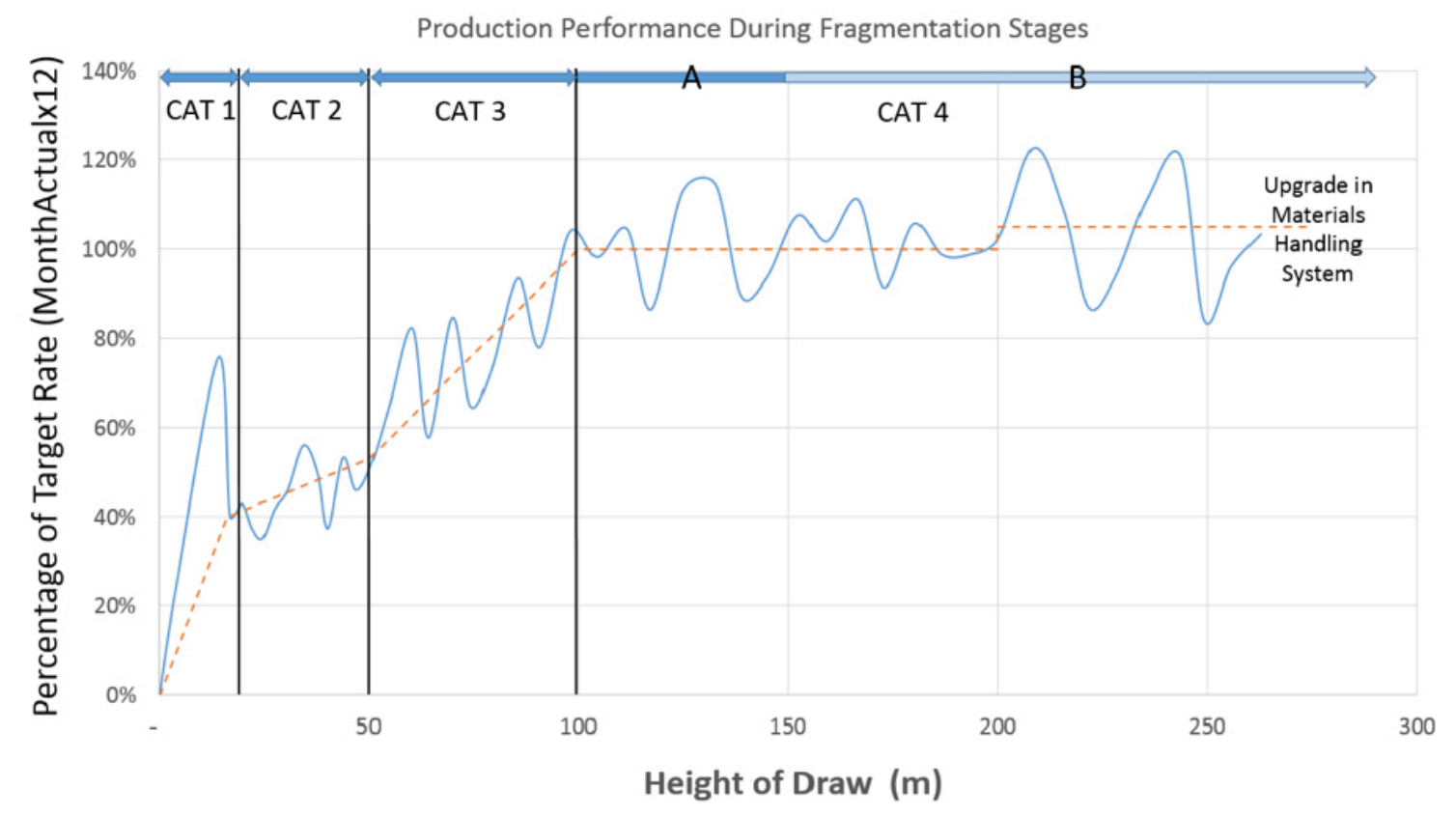

Figure 1 Production performance in hard rock caves as impacted by evolution in fragmentation (Cuello \& Newcombe 2018)

The GBC and DMLZ footprints are shown in Figure 2 and Figure 3 along with domains of weaker rock that are hosted by stronger, more massive, veined rock (for a detailed summary of associated operations see Casten et al. 2016). The resulting heterogeneity in strength demands a local understanding of geotechnical properties that impact caving rates and productivity such as cave back stress, intact rock strength, vein strength and intensity as well as the presence of hydrofractures from preconditioning. The forecasting approach at PTFI specifically relies on the following activities:

- Quantifying heterogeneity in point load index (including both intact and vein failures) and the intensity of persistent weak veins, faults and fractures.

- Characterizing vein and fault patterns, properties and continuity by vein and fault type.

- Assessing Cave Propagation Factor (CPF) throughout the cave column, defined as the ratio of expected cave back stress to defected rock strength (Flores \& Karzulovic 2003).

- Development of a set of predictive relations (nomograms) to estimate caving rate, primary and secondary fragmentation based on the above.

- Collection of monitoring data for calibration, including cave back fracture limits and drawpoint fragmentation, hangup frequency and productivity. 


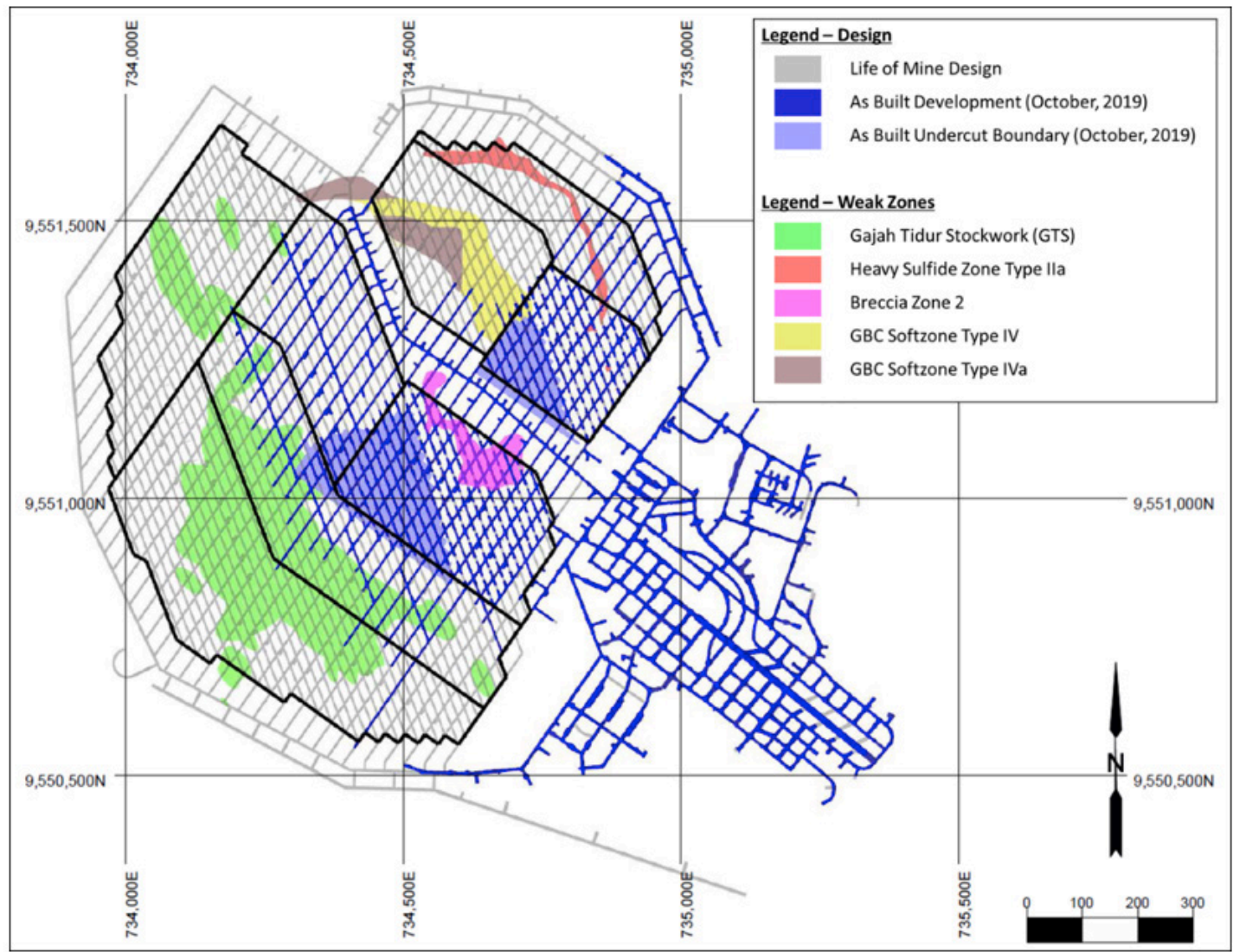

Figure 2 GBC footprint with current undercut geometry and weak geotechnical domains

The results of forecasting are presented in the form of block models, footprint heat maps and time/ tonnage-based drawpoint charts. Once calibrated, they can be used by engineering and production teams to anticipate conditions in different sectors of the cave. For example:

- Cave shaping. Caving rate and productivity forecasts can be used in draw scheduling to help achieve the target or ideal cave shape as dictated by the Cave Management Plan (CMP).

- Preconditioning planning. Volumes of low CPF ground in the column suggest difficult to cave areas that would benefit from hydraulic fracturing (or additional treatment).

- Wet muck forecasting. A forecast of high fines content at the drawpoints coupled with a forecast of water inflow to the cave helps to estimate the spatial and temporal distribution of wet muck on the footprint.

- Verification of secondary breakage plans and equipment needs. Forecasting of hangup frequency helps the team assess whether there are adequate resources to bring down hangups in the area.

- Adjustment of Production Rate Curves (PRC) curves. PRC curves can be developed that are tailored to panel and drawbell-specific geotechnical and operational conditions in order to improve accuracy of PC-BC and other recovery forecast tools.

This paper outlines the components of the methodology and the workflow that has been established at PTFI to generate forecasts for production and engineering and presents early results of the calibration process and practical application to planning at GBC and DMLZ. 


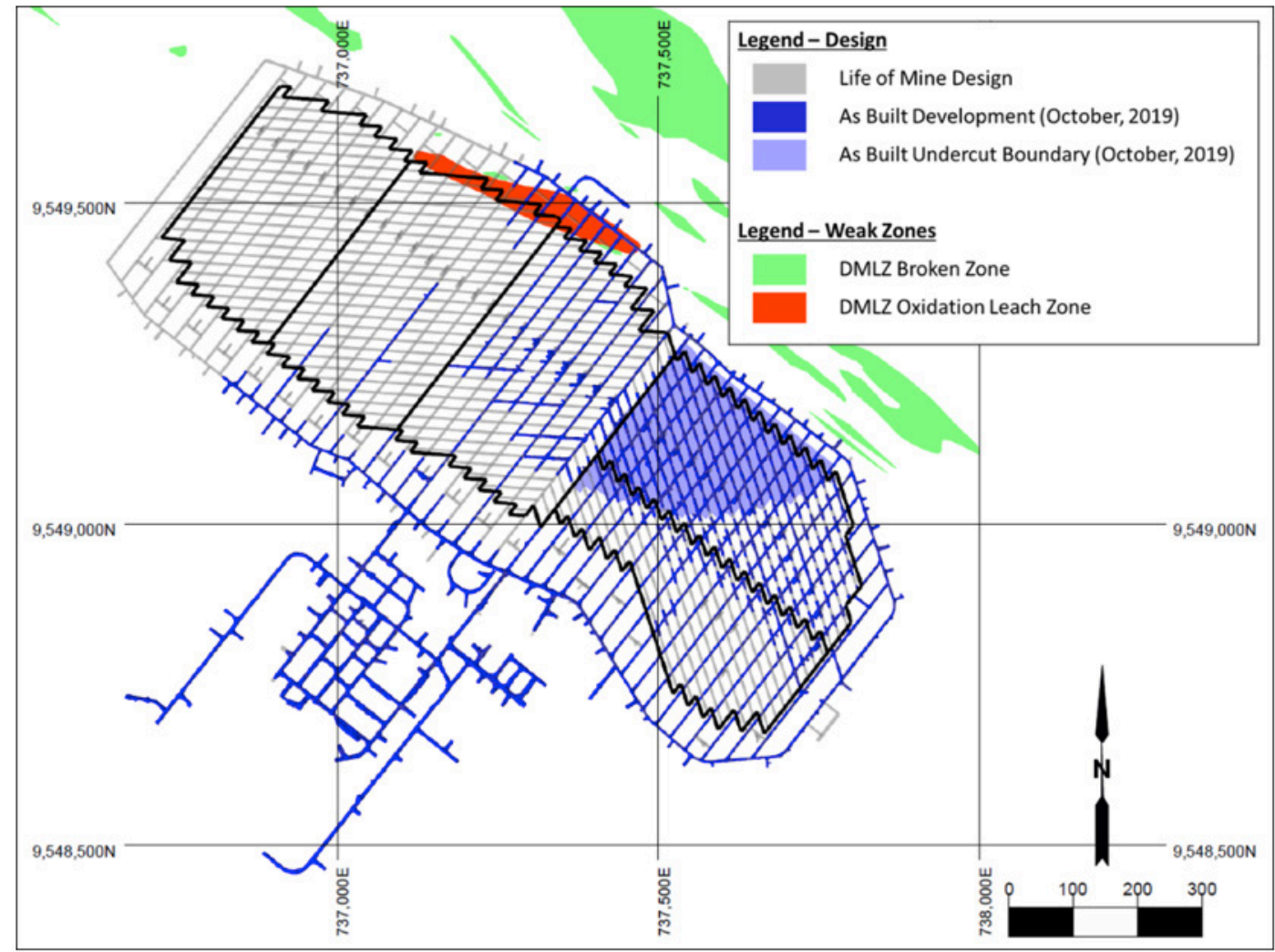

Figure 3 DMLZ footprint with current undercut geometry and weak geotechnical domains

\section{Methodology}

The main components of the productivity forecasting methodology at PTFI are outlined in Figure 4. These are supplemented by model-derived nomograms for fragmentation prediction and monitoring data for calibration. The methodology shares some features with other recently developed approaches to fragmentation and productivity forecasting that recognize the importance of considering heterogeneity in cave back stress, intact/vein strength and discontinuity intensity. For example, cave back stress block models, point load index block models and flow mixing models have been coupled to aid in primary and secondary fragmentation forecasting at Niobec Mine (Garza-Cruz et al. 2014; Fuenzalida et al. 2014) while fracture intensity block models have been developed and applied to similar forecasting at both Cadia Mine (Rogers et al. 2010; Brunton et al. 2016) and New Afton Mine (Munkhchuluun et al. 2017; Nadolski et al. 2018). New Afton Mine has also coupled primary fragmentation block models with flow mixing models to develop drawpoint-based forecasts (Munkhchuluun et al. 2018) and Castro \& Cuello (2018) provide an example of how drawpoint monitoring data can be used to enhance productivity forecasting through the development of site specific hangup frequency relations. The methodology developed for PTFI brings all these elements together in a single workflow with a strong foundation of vein-based rock mass characterization, geostatistical block models, state-of-the-art three-dimensional modelling and simulation tools and both cave back and drawpoint-based monitoring data. The following sections discuss each of the components of the methodology in greater detail, followed by a presentation of example forecast outcomes, early calibration results and plans for ongoing calibration and improvement. 


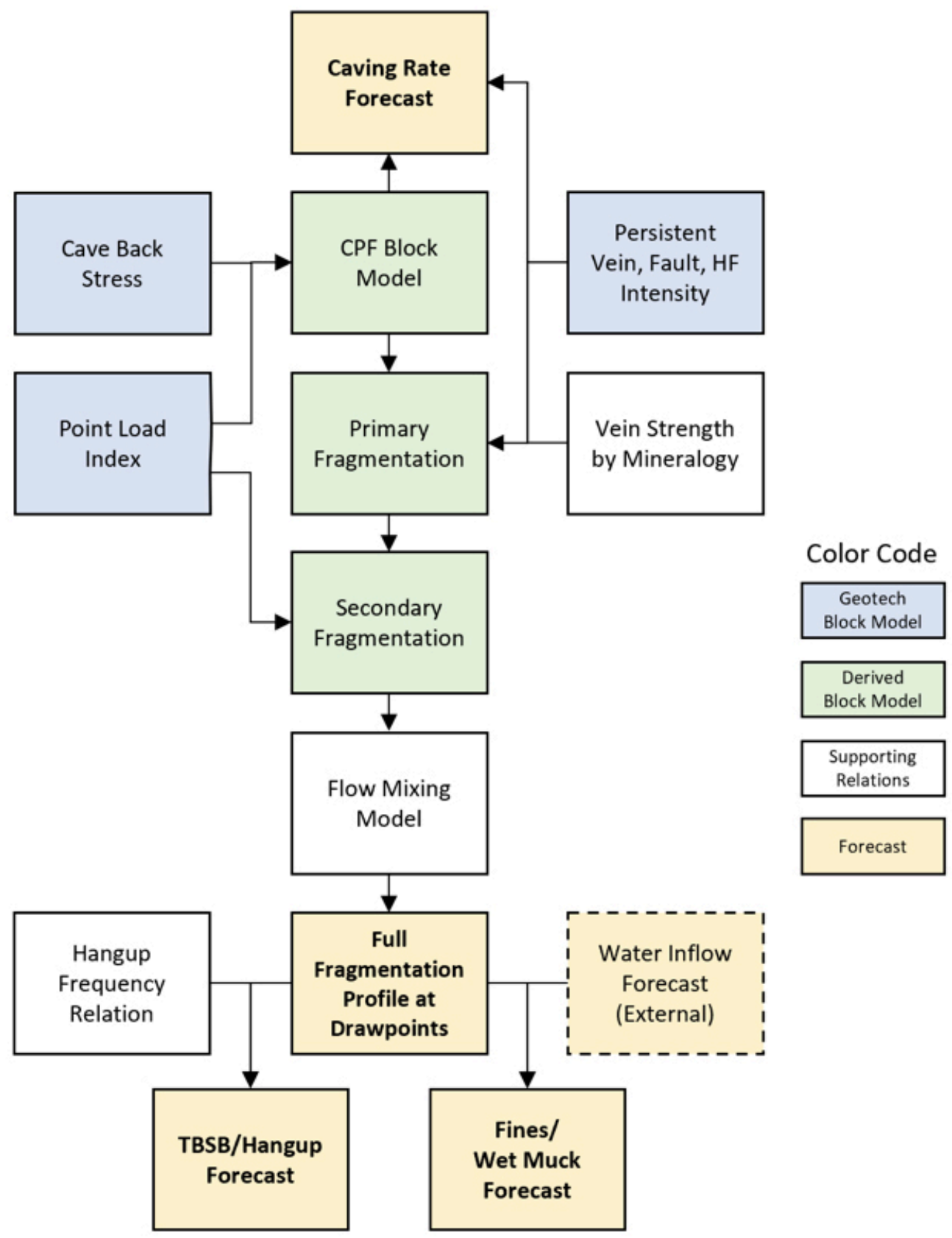

Figure 4 Main components of the cave productivity forecasting methodology

\subsection{Geotechnical block models}

The massive, veined, heterogenous nature of the PTFI rock masses presents a challenge to rock mass characterization. Geological Strength Index (GSI) is generally not applicable to the estimation of rock mass strength since there are relatively few open joints and GSI values are generally greater than 65, especially at DMLZ (e.g. see Bewick et al. 2019). As a result of this, characterization efforts are focused primarily on the geology with alteration, type and intensity of veining and major structures. This information is developed into block models of weak, persistent vein and fault intensity and point load index, with the latter accounting for variability in both intact strength and the intensity and strength of more randomly oriented veins (stockwork). 


\subsubsection{Persistent vein, fault and hydrofracture intensity}

Preliminary block models of vein intensity were developed for GBC (gypsum veins) and DMLZ (sulphide veins) based on vein counts made during core logging. The confidence in these block models is relatively low since historical core logging was not as highly focussed on logging vein frequency by mineralogy. Work is ongoing to improve the reliability of these block models based on more recent drilling and logging incorporating more detailed vein logging. Block models of small-scale fault intensity have yet to be developed but examination of the spatial trends in intensity from mapping and logging suggests that intensity is strongly related to proximity to major faults. A wireframe is used to delineate blocks that are thought to have been hydrofractured one or more times during preconditioning, which was done on a nominal $2.5 \mathrm{~m}$ spacing at DMLZ only.

\subsubsection{Point Load Indices}

Point load indices obtained during core logging at PTFI have been used to produced block models of expected mean Is50 for all breaks (Is50ALL), intact and multiple breaks (Is50IM) and structural and combined breaks (Is50SB). Use of Is50ALL allows for the impact of both intact rock and stockwork veins on rock strength to be considered. These block models capture the significant variability in strength of intact rock and veins that is present at GBC (see Figure 5) and form a critical component of the forecasting methodology.

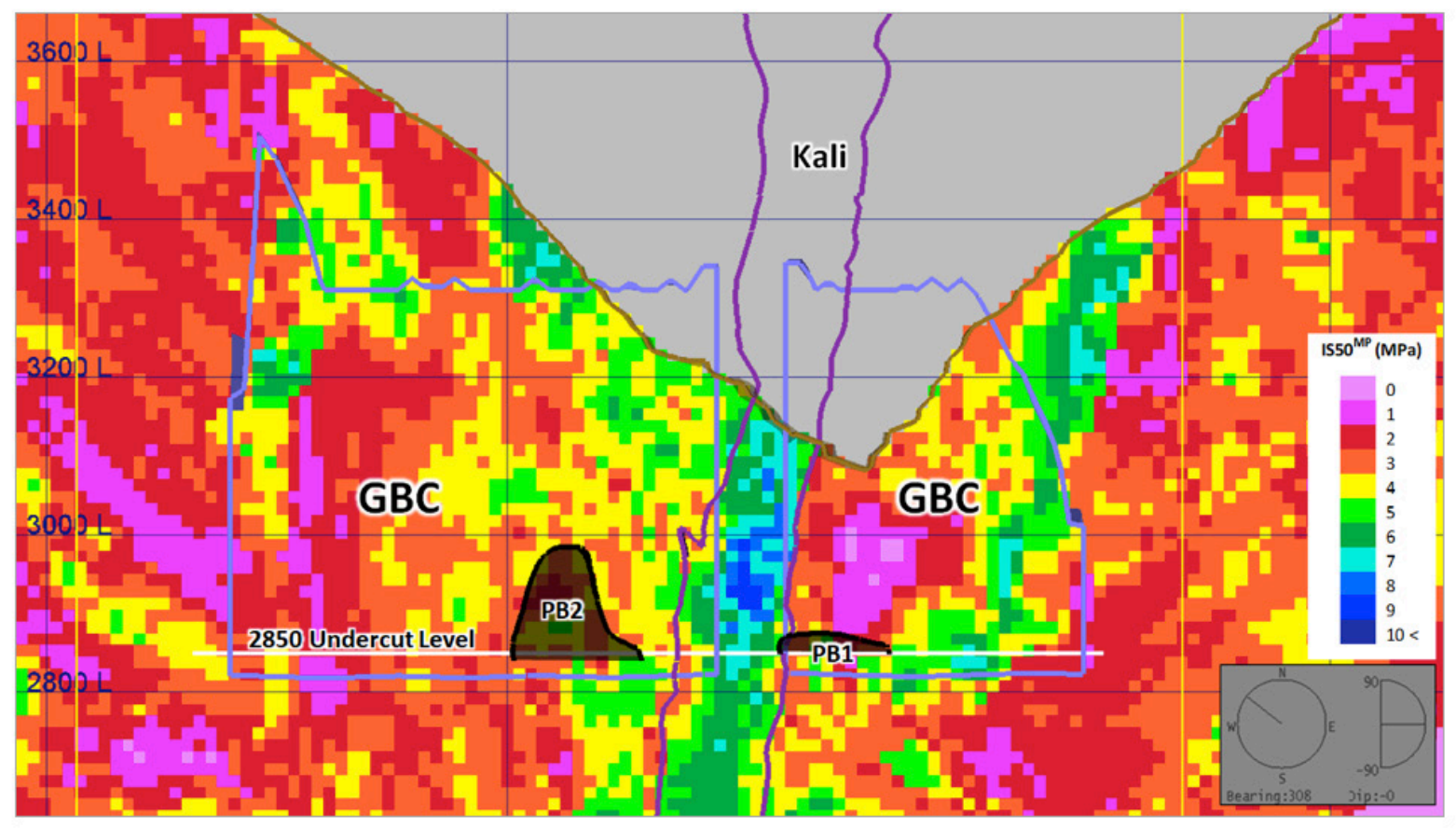

Figure 5 Block model of expected mean point load index for all break types (Is50ALL) at GBC

\subsubsection{Cave back stress}

Modelling environments were developed in FLAC3D to enable import and analysis of cave shapes for estimation of elastic cave back stresses, which are expected to exert a significant influence on primary fragmentation and caving rate. The advantages of using elastic (as opposed to inelastic) models are that they reveal the potential for cave back stresses independent of the rock mass strength and are also simple and quick to run. Estimated future cave shapes were generated following the undercut sequence, CMP guidelines and planned draw schedules for GBC and DMLZ to estimate cave back stresses throughout the entire cave column. By combining the results from multiple simulations, it was possible to produce a block model of expected maximum cave back stress (s1-s3) for life of mine at both GBC and DMLZ (e.g. see Figure 6). A number of cave back stress block models are under development and will be subject to continuous review to account for the likelihood that actual cave shapes will deviate from planned. 


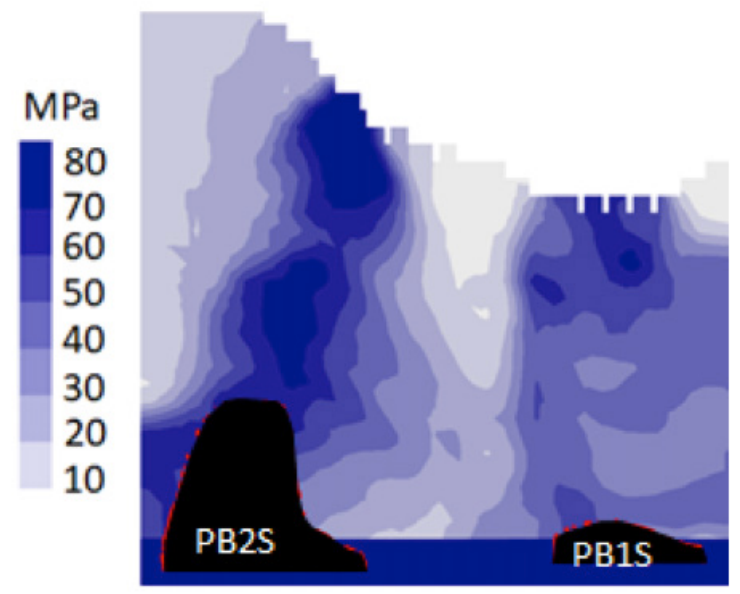

Figure 6 Block model of expected maximum cave back stress (s1-s3) for life of mine at GBC. Current cave shapes shown for reference

\section{$2.2 \quad$ Supporting relations}

\subsubsection{Vein strength by mineralogy}

The gypsum veins at $\mathrm{GBC}$ and sulphide veins at DMLZ are considered most relevant to the forecasting of fragmentation and caving since they represent the weakest persistent veins in each mine. Point load tests have been used to measure the tensile strength of many of the vein types by appropriate alignment of the vein with the loading platens. The point load indices were multiplied by a factor of 1.25 to obtain direct tensile strength (DTS) (ISRM 1989). Results of the tests indicated on average, Type 5 veins (gypsum+/-sulfide+/-anhydrite) were among the weakest and Type 3 (quartz+/-anhydrite+/-sulfide) were the strongest (see mean values in Table 1). The full distribution of tensile strength was employed when representing veins within the SRM tests.

Discrete (vein) failure types were also reviewed for selected Uniaxial Compressive Strength (UCS), Triaxial Compressive Strength (TCS), and Brazilian Tensile Strength (BTS) tests in PTFI's rock test database in order to estimate shear strengths of different vein types at the GBC and DMLZ. This analysis revealed that the origin of the sample (GBC or DMLZ) as well as the rock lithology and alteration types (i.e., PTFI's geotechnical domains) do not show a clear influence on the vein strength and that the vein strengths appeared to be more closely related to the vein mineralogy and vein characteristics. Therefore, shear strength parameters (cohesion and friction) were developed per vein mineralogy.

Table 1 Vein tensile strength estimated from point load testing

\begin{tabular}{|c|c|c|c|}
\hline Vein type & Major mineral & Minor mineral & $\begin{array}{c}\text { Mean tensile } \\
\text { strength (MPa) }\end{array}$ \\
\hline $2 \mathrm{a}$ & Sulphide & Anhydrite+/-Quartz+Sericite Halo & 0.5 \\
\hline $2 \mathrm{~b}$ & Sulphide & Anhydrite+/-Quartz & 3.9 \\
\hline 3 & Quartz & Anhydrite+/-Sulphide+/-Sericite Halo & 3.9 \\
\hline 4 & Anhydrite & Sulhpide+/-Quartz+/-Dark Biotite & 2.1 \\
\hline 5 & Gypsum & Sulhpide+/-Anhydrite & 1.1 \\
\hline
\end{tabular}




\subsubsection{Flow mixing model}

The flow mixing model is used to generate a forecast of material draw from a drawbell by combining it with the secondary fragmentation block model. Both REBOP (Pierce 2010; Itasca 2015) and PC-BC (Diering 2000) are used as mixing models within the forecasting methodology. REBOP is used for quantifying the sensitivity of forecasts to flow zone width, secondary fragmentation and fines migration as a part of research and development while PC-BC is used to generate the quarterly productivity forecasts for operational use. Only vertical mixing is presently considered, although future forecasts will account for lateral mixing due rilling in air gaps and along static cave boundaries if necessary.

\subsubsection{Hangup frequency relation}

Production in drawpoints that are hung-up ceases until the secondary breakage units are deployed and have removed the hung-up blocks, therefore an increase in hangup frequency results in a loss of productivity. Experience at DMLZ Mine suggests that maintaining or sustaining flow usually assists in maximizing the tonnes between secondary breakage (TBSB), specifically where low draw orders are received. This suggests that TBSB is not just related to the percentage of oversize $\left(>2 \mathrm{~m}^{3}\right)$ reporting to a drawpoint but to the draw rate as well. A candidate hangup frequency relation was developed for DMLZ that was subsequently adjusted within the forecast calibration process to achieve a reasonable match between actual and model derived TBSB for 2019.

\subsection{Model-derived predictive nomograms}

Recent primary and secondary fragmentation estimates at PTFI have been generated from the Block Cave Fragmentation (BCF) software package (Esterhuizen 2005). While this continues to be used for forecasting, it presents certain limitations. For example, studies (e.g., Nadolski 2018) have described BCF's limitations, particularly around the ability to forecast fines content and the provision of unreliable estimates on primary fragmentation when veined rock masses are considered. Furthermore, BCF was developed primarily from case studies in jointed rock masses as opposed to the massive to moderately jointed and veined rock masses present in DMLZ and GBC. The forecasting approaches must therefore be calibrated to specific site experience and augmented with more advanced methods of assessment to become reliable and useful for mine planning and scheduling purposes. In this current methodology, prediction of primary and secondary fragmentation rely on mechanics-based tools, namely Synthetic Rock Mass (SRM) testing and REBOP flow simulations.

\subsubsection{Primary fragmentation from synthetic rock mass testing}

The connectivity of the weak persistent veins and small-scale faults are expected to strongly influence the primary fragmentation process at PTFI. The Discrete Fracture Network (DFN) modelling software FracMan (Golder 2019) was used to develop three-dimensional geometric representations of the persistent vein and fault networks that were calibrated to data collected during core logging, photogrammetry mapping and drift fault mapping. These were then embedded within Synthetic Rock Mass (SRM) samples representing the intact rock and stockwork vein network and tested under representative cave back stresses to estimate primary fragmentation (Figure 7 and Figure 8). Hydrofractures were also introduced as persistent planar features in some samples. The SRM samples were built in 3DEC (Itasca 2016), in which the rock mass is represented by a collection of interlocked tetrahedral blocks bonded at their contacts (Garza-Cruz \& Pierce 2014; Darcel et al. 2015). The samples effectively represent different sections of the cave back with typical dimensions on the order of $20 \mathrm{~m}$ (span) x $10 \mathrm{~m}$ (height) x $12 \mathrm{~m}$ (width). 


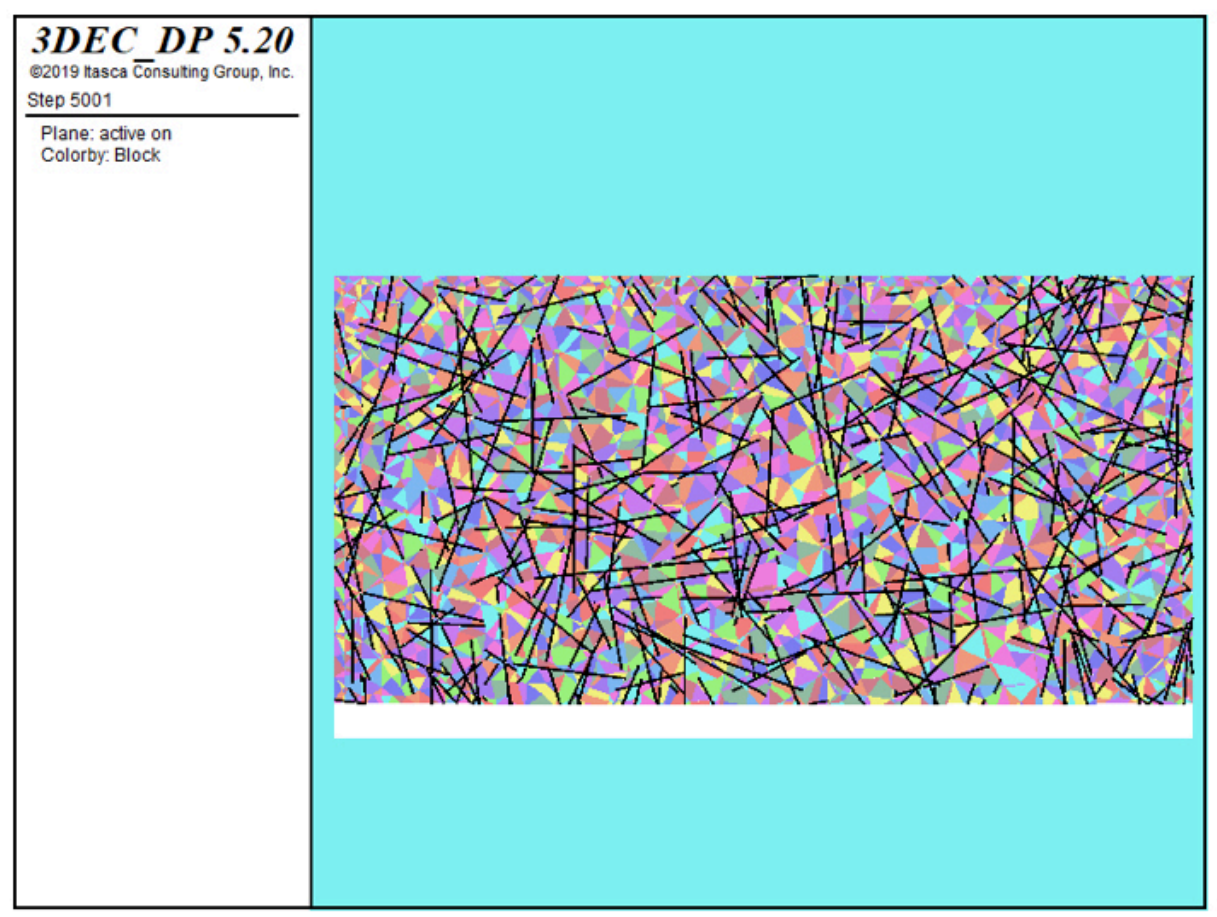

Figure 7 SRM sample of GBC rock mass with a persistent gypsum vein and small-scale fault networks (defined via DFN simulation) overprinted onto a background dense vein network (stockwork). Cave back stresses are applied laterally and the sample is relaxed gradually from below to induce primary fragmentation. Sample is $20 \mathrm{~m}$ wide
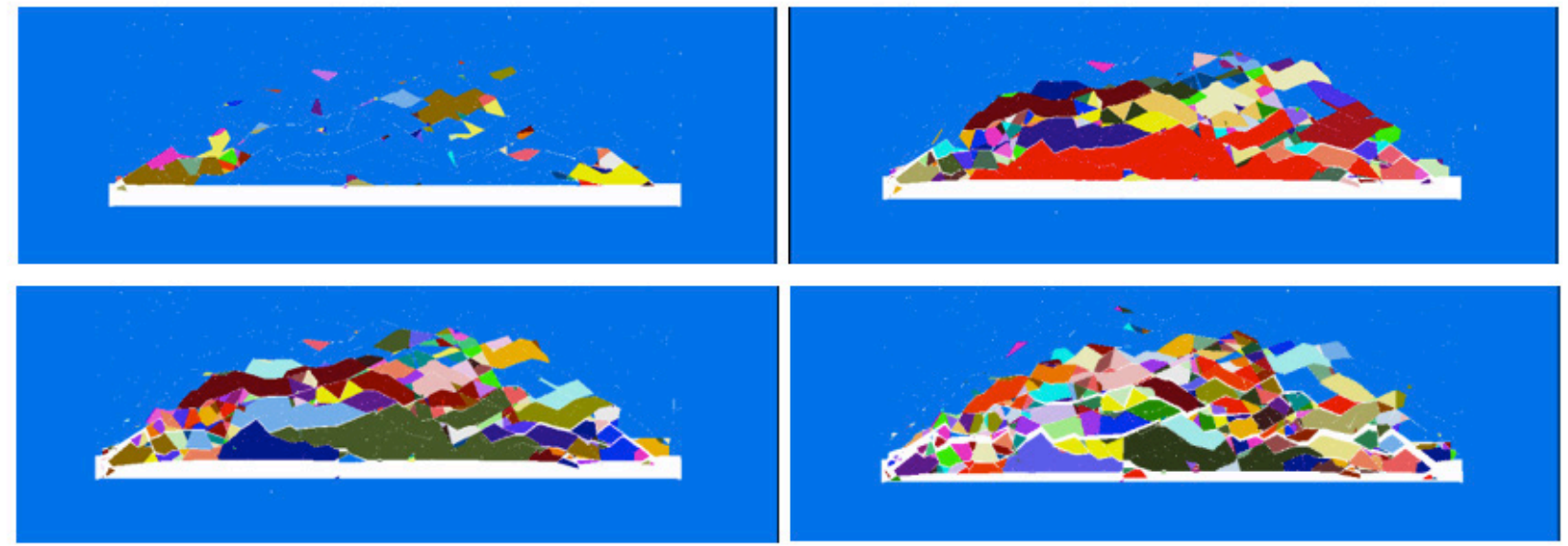

Figure 8 Sequence of emerging primary fragmentation from a GBC SRM test

A range of SRM tests were conducted to produce predictive nomograms for primary fragmentation based on CPF and persistent vein intensity (Figure 9). At low CPF values, local caving and fragmentation are hindered, independent of the persistent vein intensity. As one moves down and to the right along a given isoline (representing a specific weak persistent vein intensity), the positive impact of increasing CPF ( $x$-axis) on both the percentage oversize in primary fragmentation (primary $y$-axis) and caving rate (secondary $y$-axis) can be estimated. It can be noted that the weak persistent veins aid in the process of fragmentation/caving at lower CPFs (0.75-1.1) but at higher CPFs (>1.1), the fragmentation is coarser when compared to a rock mass with no persistent veins/faults. 


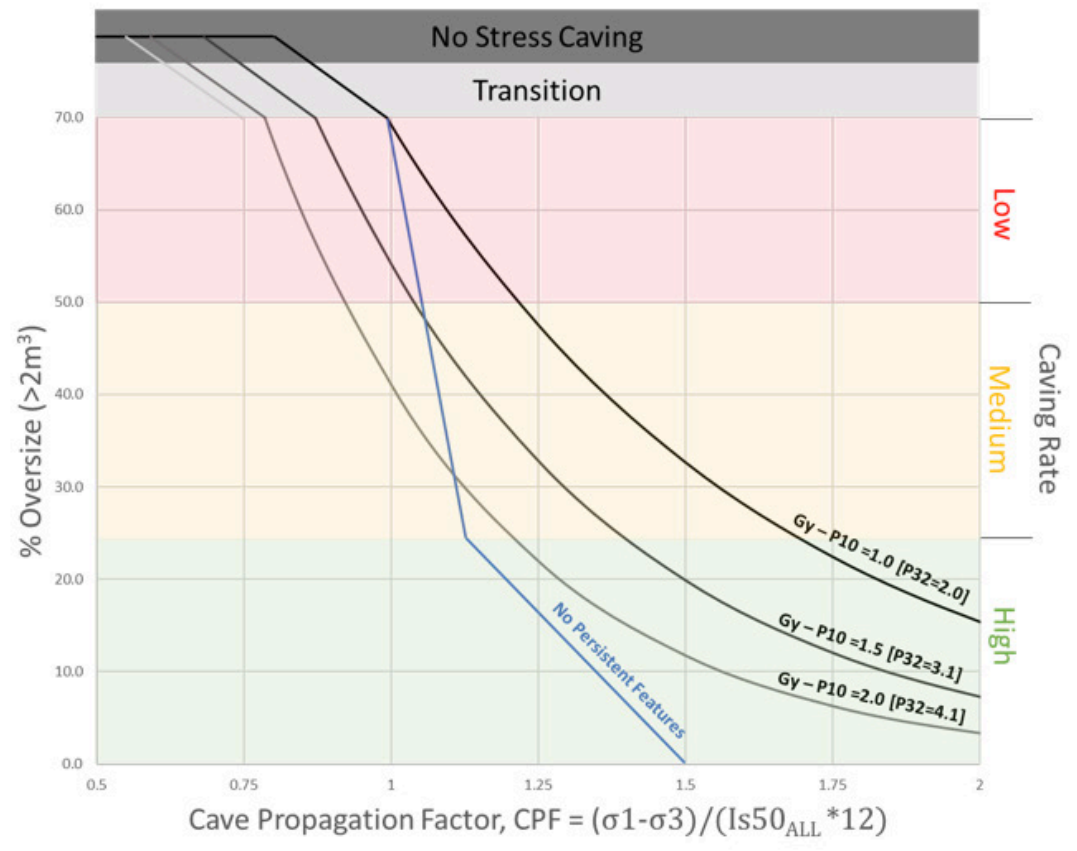

(a)

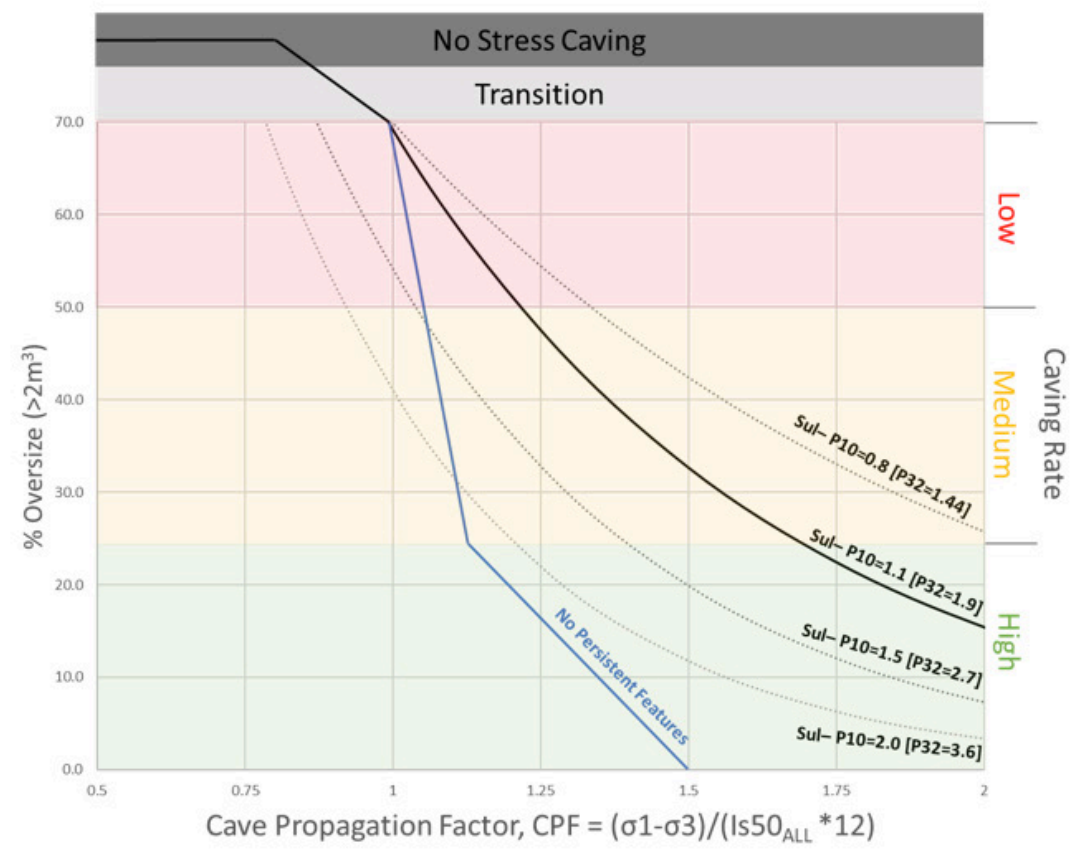

(b)

Figure 9 Predictive model-derived nomograms for primary fragmentation and caving rate at (a) GBC and (b) DMLZ. The isolines represent different weak persistent vein intensities, expressed as a vein frequency per metre (P10) and equivalent vein area per unit volume (P32)

In the nomogram, CPF is defined as the ratio of cave back stress (s1-s3) to the strength of the defected rock between the persistent veins, defined as IS50ALL x 12. This point load index multiplication factor was revealed by the SRM testing, in which spalling is the dominant failure mechanism leading to primary fragmentation. The value of the factor makes sense in the context of conversion factors from Is 50 to UCS that have previously been established at PTFI (in the range of 20-25) and spalling theory, which suggests onset of spalling at 30-50\% of the UCS (Martin 1993).

These forecasting nomograms are used within the methodology to convert local block model estimates of cave back stress, Is50ALL and persistent vein intensity into preliminary forecasts of local CPF, primary 
fragmentation and caving rate. The nomogram only provides a starting point for forecasting. Calibration is essential to the process, and the nomograms should be updated continuously based on monitoring of real cave and drawpoint performance.

\subsubsection{Secondary fragmentation from REBOP flow simulations}

Estimates of secondary fragmentation are necessary to convert expected primary fragmentation into a fragmentation profile that can be expected at the drawpoints, including specification of likely oversize and percentage of fines. For this purpose, a series of generic REBOP simulations were conducted over a wide range of primary fragmentation and rock block strength to develop a predictive nomogram for these quantities based on Is50ALL and the height of draw (HoD). The purpose of running generic cases was to cover off as many likely combinations of primary fragmentation and rock block strength as possible for GBC and DMLZ. Only vertical mixing was considered in the simulations.

Examination of the results from simulations on ranges of primary fragmentation and fragment strength reveals that the proportional reduction in oversize material (i.e. drawpoint oversize/primary oversize-100\%) is relatively independent of the initial fragment size distribution. As a result, it is possible to normalize the results and express them in a single nomogram defining percentage of oversize reduction as a function of the mean Is50 and height of draw (Figure 10). This graph also presents the increase in \%fines reporting to the drawpoint with HoD, assuming zero initial fines (on primary fragmentation). The nomogram predictions assume uniform draw conditions and the absence of fines migration and rilling. This nomogram is used to convert primary fragmentation predictions into drawpoint fragmentation estimates (oversize and fines) within the forecasting workflow.

\section{$3 \quad$ Forecasting and calibration}

The first step in forecasting is to generate the CPF block model by taking the ratio of the cave back stress to the point load strength $\times 12$. Once CPF is defined, it can be combined with the intensity block model, height above the extraction level and the predictive nomograms to generate primary and secondary fragmentation block models. The secondary fragmentation block model is key as it attempts to predict how the primary fragments generated in each block will manifest themselves in terms of size when they reach the drawpoint. This is the block model that is queried with the flow mixing model and hangup frequency relation to generate drawpoint forecasts.

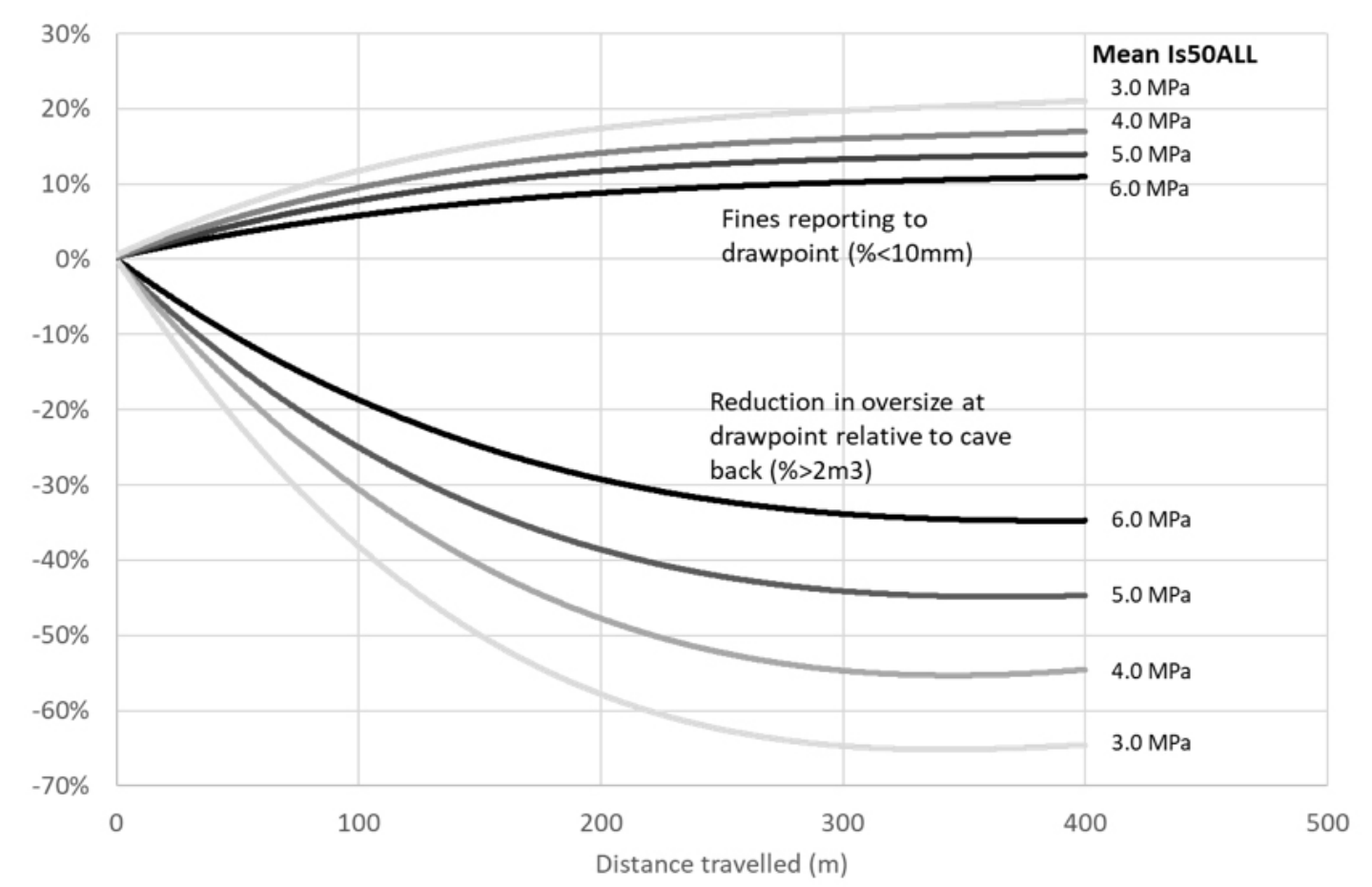

Figure 10 Secondary fragmentation forecasting chart to estimate fines $(\%<10 \mathrm{~mm})$ and reduction of oversize $(\%>2 \mathrm{m3})$ at the drawpoint relative to primary fragmentation 


\subsection{Visualization}

Forecasts take the form of charts, showing the expected trends in \%oversize, \%fines, hangup frequency or productivity. Figure 11 shows an example of the drawpoint hangup frequencies expected at DMLZ to the end of 2022, presented as a whisker plot of TBSB for all active drawpoints. The forecasts show trends in productivity that are consistent with the evolution in fragmentation-driven production performance noted in deep hard rock caves (Figure 1) but with drawpoint-specific variations from the general trend due to drawpoint-specific overlying heterogeneities in defected rock strength (Is50), cave back stress and persistent vein and/or hydrofracture intensity.

Forecasts can also take the form of heat maps with drawpoints on the footprint colored by expected \%oversize, \%fines, hangup frequency or productivity for a fixed future HoD or point in production or as an average over the life of the drawpoint (or some other period). Figure 12 shows the expected hangup frequency for November 2022, presented as a heat map of TBSB. The forecast reveals sectors on the footprint where higher productivity can be expected due to higher TBSB as well as sectors likely to require more intense secondary breakage efforts.

Caving rate forecasts take the form of contour plots through the forecast block model. Figure 13 shows an example of the first pass (uncalibrated) caving rate forecast for DMLZ. The contour plots reveal areas where high caving rates and preferential cave growth could be expected as well as difficult-to-cave regions that might represent targets for hydraulic fracturing.

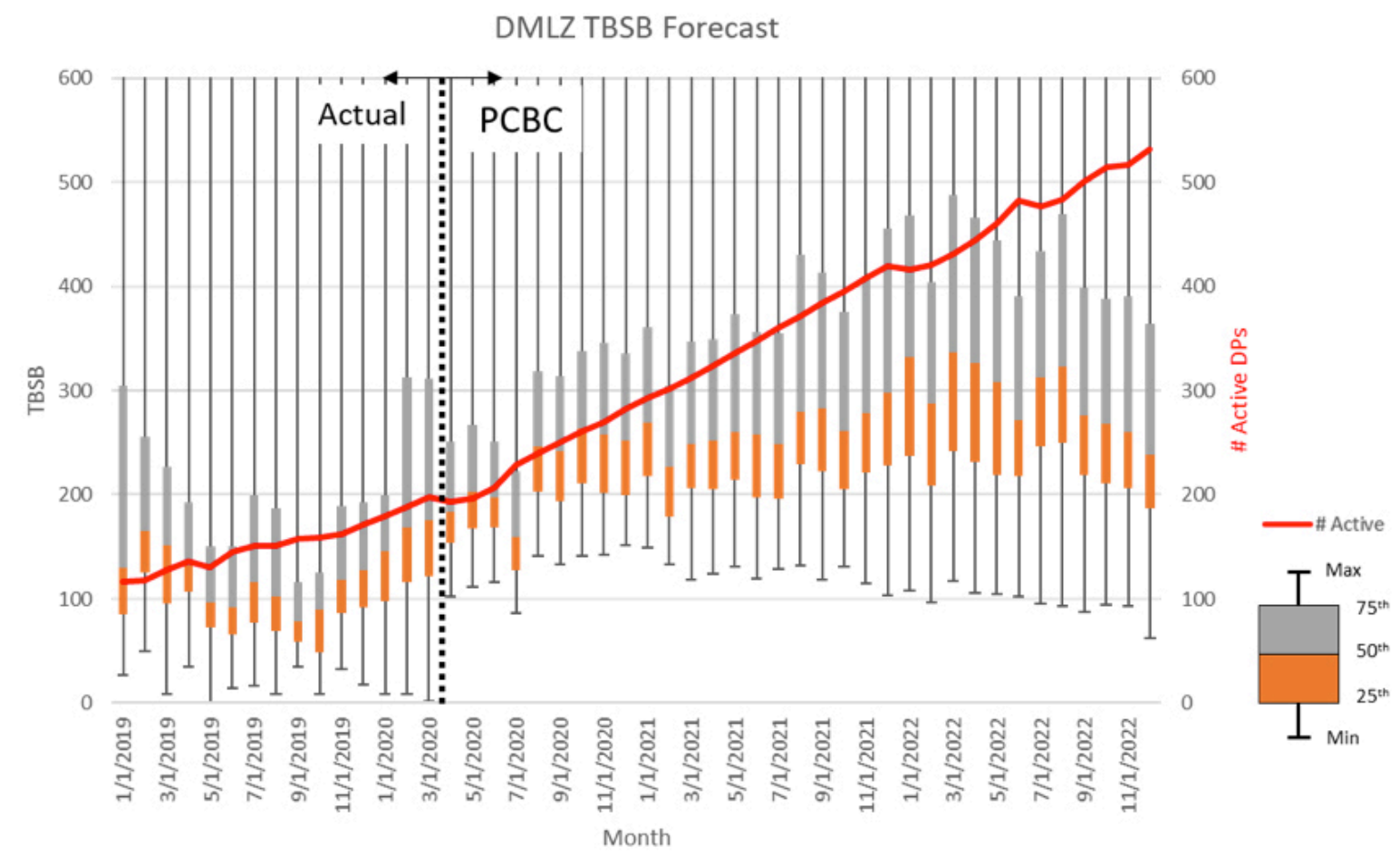

Figure 11 Hangup frequency forecast chart for DMLZ showing expected range in TBSB for all active drawpoints to the end of 2022 


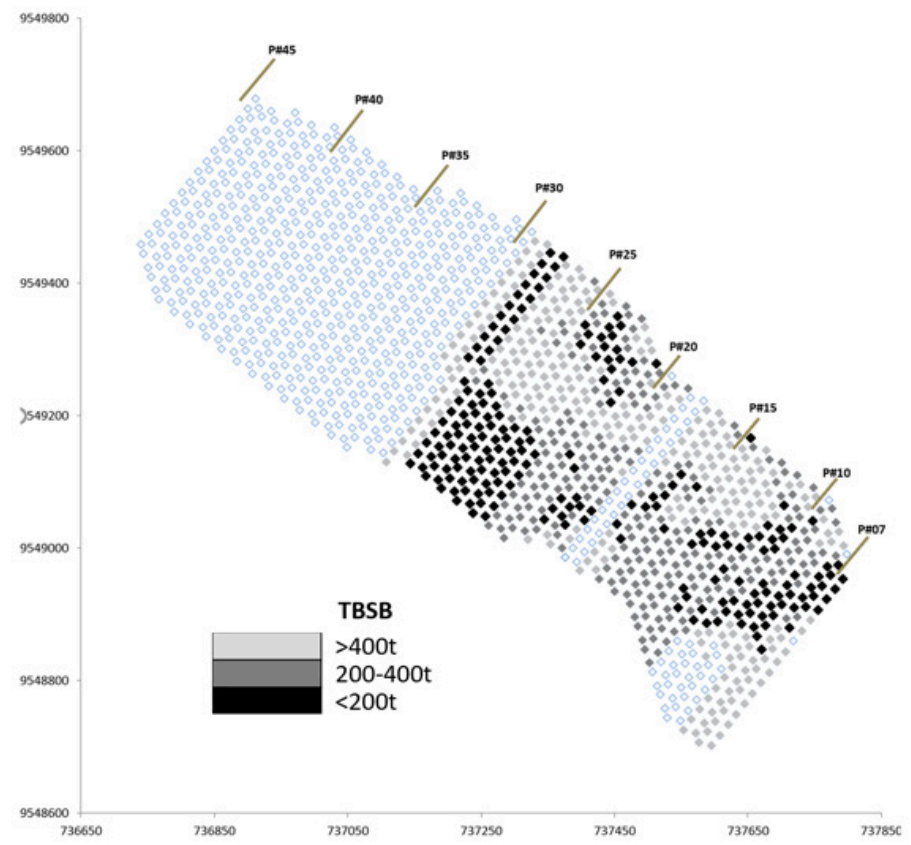

Figure 12 Hangup frequency forecast heat map for DMLZ showing expected distribution of TBSB across the footprint in November 2022

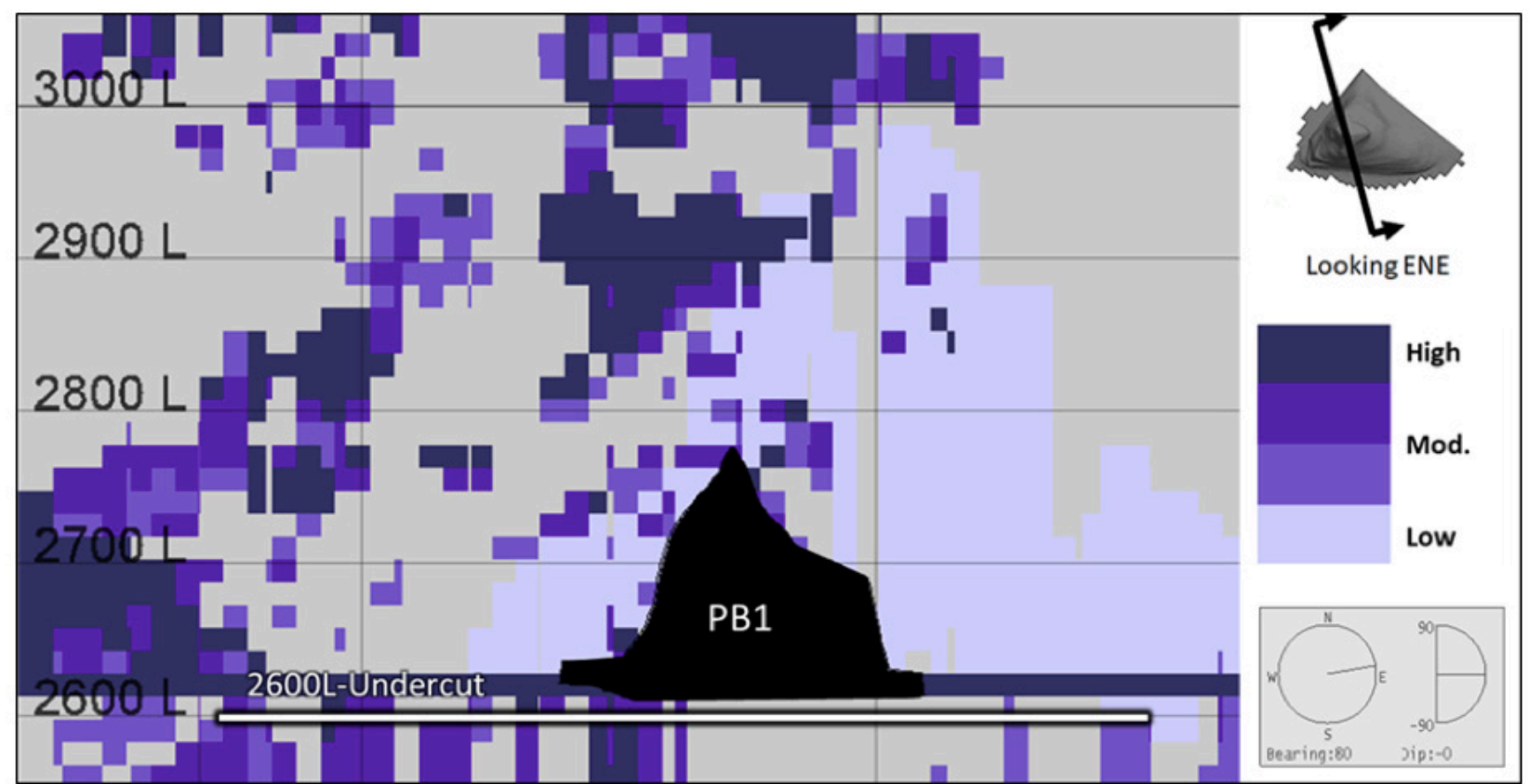

Figure 13 First pass (uncalibrated) caving rate forecast plots for DMLZ showing expected relative caving rate in the column (current cave shape indicated in black)

\subsection{Calibration}

Calibration to date has focussed on prediction of hangup frequency and will be expanded to include caving rate and fines entry. Monitoring rates of advance in the cave back and fragmentation and productivity at the drawpoints is critical to maximizing the reliability of forecasting and obtaining real time feedback on cave performance. Currently collected drawpoint data include rock type, fragment size mapping, hangup frequency/type, planned and achieved productivity, shape factor and vein breakage data. The drawpoint fragmentation measures have a known bias resulting from the presence of blasted material in the drawpoint (from secondary blasting activities) during mapping and the absence of the largest fragments (which hangup and are not visible in the drawpoint). As a result, oversize forecasts are 
directly correlated to monitored hangup frequency rather than mapped fragmentation. Figure 14 shows the results of calibration of the forecasting methodology to hangup frequency trends at DMLZ in 2019, expressed as side-by-side whisker plots of the predicted versus actual monthly TBSB for all drawpoints. Adjustments were made primarily to the hangup frequency relation in order to achieve the reasonable match shown. Further adjustment of this relation and other inputs and relations will likely be required as the caves mature and/or secondary breakage practices change and so the forecasting tool will be updated on a regular basis to best reflect observed conditions.

DMLZ TBSB Actual vs Model

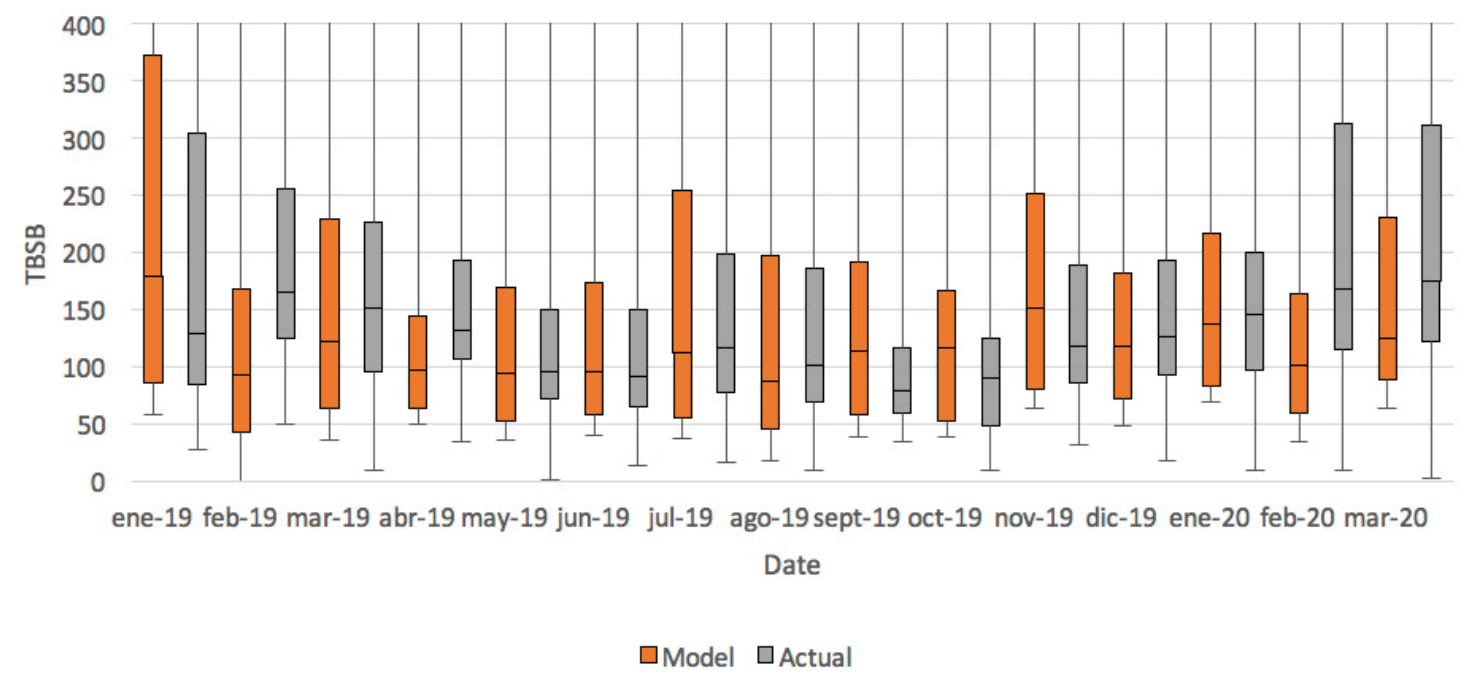

Figure 14 Comparison of back analysed to actual hangup frequency distribution following calibration of the forecasting methodology to 2019-2020 TBSB data from DMLZ

\section{$4 \quad$ Conclusions}

A recently developed approach to forecasting of local caving rates and drawpoint productivities at PT Freeport Indonesia's (PTFI) Grasberg Block Cave (GBC) and Deep Mill Level Zone (DMLZ) mines has been presented. The methodology has been calibrated for hangup frequency prediction and is used to assist production planning in managing the fragmentation-driven evolution in production performance. The local nature of the forecasting methodology is driven by the heterogeneous nature of the rock mass domains, which demands a local understanding of cave back stress relative to defected rock strength (CPF), the patterns, properties and continuity of persistent weak veins and the presence of hydrofractures from preconditioning. The results of forecasting are presented in the form of block models, footprint heat maps and time/tonnage-based drawpoint charts. Monitoring rates of advance in the cave back and fragmentation and productivity at the drawpoints will be critical to understanding the reliability of the forecasting tool by comparing the predicted values against the observed performance as mining progresses. A robust data set is being collected to support this effort and includes rock type, fragment size mapping, hangup frequency/type, planned and achieved productivity, shape factor and vein breakage data. These will be used to analyse the performance of the cave and subsequently productivity. Calibration efforts to date have focussed on hangup frequency forecasting with reasonable matches obtained between actual and back analysed TBSB to date. The forecasting tool will be updated on a regular basis to reflect the actual conditions and to incorporate new geotechnical information as it becomes available.

\section{Acknowledgements}

The authors would like to acknowledge contributions to this work from Jacques Tshisens, BriAnna Hoffman, Christian Cancino, Derek Badner and Rob Bewick. 


\section{References}

Bewick, RP, Campbell, R, Brzovic, A, Schwarz, A \& Pierce, M 2019, 'Incorporating Veined Rock Mass Characteristics into Engineering Design and Caving', In Proceedings 53rd US Rock Mechanics Symposium, Brooklyn, ARMA.

Brunton, I, J Lett, \& T Thornhill 2016, 'Fragmentation prediction and assessment at the Ridgeway Deeps and Cadia East Cave operations', in C Carr \& G Chitombo (eds), Proceedings of MassMin 2016, pp. 9-11.

Carlson, G, Tyler D, DeWolfe, C \& Lorig, L 2004, 'Understanding gravity flow for mix and dilution modeling at Henderson Mine', in Proud to be miners (Proceedings, MassMin 2004, Santiago, August 2004), eds A Karzulovic and MA Alfaro, Mineria Chilena, Santiago, pp. 231-237.

Casten, T, Priatna, A \& Rumbino, H 2016, ‘Deep Mill Level Zone - from feasibility to production', in C Carr \& G Chitombo (eds), Proceedings of MassMin 2016, Australasian Institute of Mining and Metallurgy, Sydney, pp. 681-688.

Castro, R \& Cuello, D 2018, 'Hangup analysis and modelling for Cadia East PC1-S1 and PC2-S1', in Y Potvin \& J Jakubec (eds), Proceedings of the Fourth International Symposium on Block and Sublevel Caving, Australian Centre for Geomechanics, Perth, pp. 233-246.

Cuello, D \& Newcombe, G 2018, 'Key geotechnical knowledge and practical mine planning guidelines in deep, high-stress, hard rock conditions for block and panel cave mining', in Y Potvin \& J Jakubec (eds), Proceedings of the Fourth International Symposium on Block and Sublevel Caving, Australian Centre for Geomechanics, Perth, pp. 17-36.

Darcel, C, Ghazal, R, Le Goc, R, Fuenzalida, M \& Pierce, M 2015, 'Development of Advanced Charts for Cave Mine Design and Operation: Primary Fragmentation Prediction, SRM-Based Charts', Report to Mass Mining Technology Project (MMT3) $2013-2016$.

Diering, T 2000, 'PC-BC: A block cave design and draw control system', Proceedings of MassMin 2000, pp. 301-335.

Esterhuizen, GS 2005, 'Block Cave Fragmentation (BCF) version 3.05 - A program to predict block cave fragmentation'.

Flores, G \& Karzulovic, A 2003, 'Geotechnical Guidelines for a Transition from Open Pit to Underground Mining: Geotechnical Guidelines, Caving Propagation'; Report to International Caving Study II, July.

Fuenzalida, M, Garza-Cruz, TV, Pierce, ME \& Andrieux, P 2014, 'Application of a methodology for secondary fragmentation prediction in cave mines', in Proceedings Caving 2014, 3rd International Symposium on Block and Sublevel Caving, Santiago, Chile, pp. 318-327

Garza-Cruz, TV, Fuenzalida, M, Pierce, ME \& Andrieux, P 2014, 'A 3DEC-FLAC3D model to predict primary fragmentation distribution in cave mines', in Proceedings Caving 2014, 3rd International Symposium on Block and Sublevel Caving, Santiago, Chile, pp. 146-158

Garza-Cruz, TV \& Pierce, M 2014, 'A 3DEC Model for Heavily Veined Massive Rock Masses', in Proceedings, 48th US Rock Mechanics/Geomechanics Symposium (Minneapolis, Minnesota, June 2014), ARMA 14-7660. Alexandria, Virginia: ARMA.

Golder Associates 2009, 'FracMan 7.20', FracMan Technology Group, Golder Associates Inc., Seattle, Washington.

ISRM 1989, 'Suggested method for determining point load strength index', International Society of Rock Mechanics RTH32589.

Itasca Consulting Group, Inc. 2016, '3DEC — Three-Dimensional Distinct Element Code (Version 5.2)', Minneapolis: Itasca

Itasca Consulting Group Inc. 2015, 'REBOP— Rapid Emulator based on PFC (Version 4.0)', Minneapolis: Itasca.

Martin CD 1993, 'Strength of massive Lac du Bonnet Granite around underground openings', Ph.D. Thesis, University of Manitoba, Canada; 1993.

Munkhchuluun, M, Elmo, D, Nadolski, S, Moss, A \& Klein, B 2018, 'Presence of natural fracture as an indicator of operational difficulty for cave operations', in Y Potvin \& J Jakubec (eds), Proceedings of the Fourth International Symposium on Block and Sublevel Caving, Australian Centre for Geomechanics, Perth, pp. 261-270.

Munkhchuluun, M, Elmo, D, Nadolski, S \& Klein, B 2017, 'Characterization of Rock Mass Fragmentation for Cave Mining', In 51st US Rock Mechanics/Geomechanics Symposium, American Rock Mechanics Association. 
Nadolski, S 2018, 'Cave-to-mill: mine and mill integration for block cave mines', PhD, University of British Columbia, 2018.

Nadolski, S, Munkhchuluun, M, Klein, B, Elmo, D \& Hart, C 2018, 'Cave fragmentation in a cave-to-mill context at the New Afton Mine part I: fragmentation and hangup frequency prediction', Mining Technology, vol. 127, no. 2, pp. 75-83.

Pierce, M 2010, 'A Model for Gravity Flow of Fragmentated Rock in Block Caving Mines', Ph.D. Thesis, University of Queensland.

Rogers, S, Elmo, D, Webb, G \& Catalan, A 2010, 'A discrete fracture network based approach to defining in situ, primary and secondary fragmentation distributions for the Cadia East panel cave project', in Y Potvin (ed.), Proceedings of the Second International Symposium on Block and Sublevel Caving, Australian Centre for Geomechanics, Perth, pp. 425439. 


\title{
Back analysis of cave propagation and subsidence at Cadia East Mine
}

\author{
E Ghazvinian Itasca Consulting Group, United States \\ M Fuenzalida Itasca Consulting Group, United States \\ C Orrego Newcrest Mining Limited, Australia \\ M Pierce Pierce Engineering, United States
}

\begin{abstract}
Cadia East panel cave mine is one of the three mines comprising the Cadia Valley Operations, one of Australia's largest gold mining operations, located in New South Wales. Production at Cadia East commenced in 2013 from Panel Cave 1 (PC1) with its extraction level set at a depth of 1,200 m below the surface. Currently, ore is extracted from PC1 and its neighboring panel (PC2) with an extraction level at 1,400 m depth. A critical component of effective production for Cadia East is successful cave propagation to the surface considering significant cave heights. To ensure cave performance, the rock mass immediately above the footprint of PC1 and PC2 was pre-conditioned by means of hydraulic fracturing (combined with blasting for PC1). Furthermore, a surface hydraulic fracturing program had to be instigated in the hard and competent near surface rock mass above PC1 to assist cave propagation through the final 450 $m$ and its breakthrough to the surface. This paper discusses the significance of using a strain-softening model with the ability to capture the correct mechanics of rock mass frictional strength mobilization for a precise back-analysis of cave performance. IMASS (Itasca Model for Advanced Strain Softening) was used for this study in FLAC3D. IMASS uses two-mode softening yield surfaces. The first residual envelope represents the post-peak strength, and the second residual envelope represents the ultimate rock mass residual strength. The two-mode softening allows for mobilization of high apparent friction angles at low confinement when the blocks are formed in the rock mass. This, in combination with implementation of pre- and post-conditioning of the rock mass (hydraulic fracturing program) in the simulation, were critical in the successful calibration of the model.
\end{abstract}

\section{Introduction}

The success of the Ridgeway sublevel cave at Cadia Valley Operations (CVO) has led to expansion of block caving operations, initially at Ridgeway Deeps (RWD) and more recently at Cadia East panel cave mine. Cadia is one of Australia's largest gold mining operations, located in New South Wales, is characterized by high-stress, hard rock mining conditions. The combination of a deep, high-stress environment, a competent rock mass and the ability to use very high lifts at depths between 1,200 and 1,400 m provides a unique opportunity for Cadia East to maximize return. Establishment of Panel Cave 1 (PC1) at Cadia East commenced in early 2011 with its extraction level set at a depth of 1,200 m below the surface. Official production from PC1 began in 2013. Currently ore is extracted from PC1 and its neighboring panel (PC2) with an extraction level at 1,400 $\mathrm{m}$ depth (Figure 1). Figure 2 shows the significance of achieving two propagating cave columns in Cadia East to surface from depths of up to $1400 \mathrm{~m}$ in a single lift when compared to other established block and panel caving operations (Cuello \& Newcombe 2018). Rock mass preconditioning was a key component of cave establishment at Cadia East to assist caveability, ensure the successful propagation of the cave to the surface (Manca \& Flores 2013) and manage mine induced seismicity (Lowther et al. 2016.)

Newcrest plans to further develop panel caves for the Cadia East deposit, as extensions to the current PC1 and PC2 operations, over the coming decades. Figure 1 shows the preliminary plan for the extension of the Western and Eastern caves. This instigated a back-analysis of PC1 and PC2 propagation and subsidence 